\title{
The potential utilisation of indigenous South African grasses for acid mine drainage remediation
}

\author{
Binita Ramla' and Craig Sheridan ${ }^{1 *}$ \\ 'Industrial and Mining Engineering Water Research Unit, School of Chemical and Metallurgical Engineering, University of the Witwatersrand, \\ Johannesburg, Private Bag 3, WITS 2050, South Africa
}

\begin{abstract}
Acid mine drainage (AMD) is a significant threat to the environment in South Africa and needs to be remedied. Although active treatment methods have been and are being implemented in industry, passive treatment systems involving bioremediation have the potential to be a more cost-effective and environmentally sustainable solution. Biological treatment of AMD involves the reduction of sulphate to sulphide by sulphate-reducing bacteria in the presence of a suitable organic substrate. This study tested the potential for indigenous grasses to be used as a carbon source in the bioremediation of AMD. Bioreactor experiments were conducted over a 70-day period to investigate whether indigenous grasses can be used to effectively reduce sulphate and iron concentrations, and increase the $\mathrm{pH}$ of an $\mathrm{AMD}$ solution. The results indicated that indigenous grasses hold promise for remediating AMD, as a maximum of $99 \%$ iron removal, $80 \%$ sulphate removal, and a final pH of 8.5 was achieved from initial conditions of $2000 \mathrm{mg} / \ell$ iron, $6000 \mathrm{mg} / \ell$ sulphate, and a pH of 3 . Optimal results occurred in the bioreactor with Hyparrhenia hirta grass amended with soil containing microbes, although all bioreactors effected some form of remediation compared to the control.
\end{abstract}

Keywords: AMD, DSR, indigenous grass

\section{INTRODUCTION}

In South Africa, the mining industry is a key driver of the economy. South Africa possesses large natural reserves of various metals and coal, and therefore hosts substantial mining activity (McCarthy, 2011). As a consequence of the types of ores in South Africa, which are often sulphide-based, mining operations, currently operational and abandoned, have led to the formation of acid mine drainage (AMD). $\mathrm{AMD}$ is a discharge from mining operations which is highly acidic and contains high concentrations of metals and sulphates (Manders et al., 2009). Various techniques have been proposed for its treatment; however, most are difficult and/ or costly to implement and as a result the problem of AMD decant remains unresolved. If left to discharge in an uncontrolled manner, AMD has the potential to pollute water resources and aquatic ecosystems.

The formation of AMD occurs in underground mine shafts, mine waste dumps, tailings and ore stockpiles. AMD has been observed in various mining regions within South Africa, including, but not restricted to, the Witwatersrand gold fields and the Mpumalanga and KwaZulu-Natal coal fields. Of current significance is the province of Gauteng (which includes the western, the central and the eastern basin) which includes the metropolitan city of Johannesburg. Gauteng is the most populous province in South Africa, with an area and population similar to metropolitan Los Angeles. Pumping from the void beneath Johannesburg has ceased, and uncontrolled decant of AMD is likely to occur if new

This paper was originally presented at the 2014 Water Institute of Southern Africa (WISA) Biennial Conference, Mbombela, 25-29 May 2014.

* To whom all correspondence should be addressed.

- +2711717 7592; e-mail: craig.sheridan@wits.ac.za pump stations are not constructed (Coetzee et al., 2010). In the western basin (near Krugersdorp, west of Johannesburg) water decanted from the mine void with sulphate concentrations of approximately $3500 \mathrm{mg} / \ell$ and a pH range between 2 and 3 (Coetzee et al., 2010).

In the Witbank/Middelburg area, east of Johannesburg, there are many coal mines which are abandoned (McCarthy, 2011). Many of these workings decant acidic water into local waterways which lead into the Olifants River catchment. Although neutralisation techniques are being implemented to treat the AMD in the river systems, the water is still very saline and highly concentrated with sulphates. A reverseosmosis (RO) plant has been constructed successfully at eMalahleni by Anglo American and BHP Billiton to treat AMD to potable water standards, but the cost per litre is still significantly greater than that of traditional water (McCarthy, 2011).

Most active treatments for AMD are complex, costly and time consuming (Smith, 1997; Johnson and Hallberg, 2005). As a result, there has also been much recent research on passive treatment systems. Research indicates that various materials such as limestone, sawdust, cow manure, peat, clay and turkey litter have been found to be partially successful when utilised in passive treatment systems for AMD remediation (Grubb et al., 2000). They also established that the utilisation of sugar cane bagasse provided partial treatment of acid mine drainage. Sheridan et al. (2013) investigated the use of charcoal- and slag-based constructed wetlands to provide partial remediation of AMD. Thus, there is a clear potential for waste products, or similar materials, which are rich in cellulose and readily available to be utilised for AMD remediation.

In this paper, we investigate the potential use of two indigenous grasses (Hyparrhenia hirta and Setaria sphacelata) as an organic substrate for treating AMD through the mechanism of dissimilatory sulphate reduction (DSR). 


\section{BACKGROUND}

\section{Acid mine drainage}

Acid mine drainage occurs naturally when sulphur-rich minerals from mining operations are exposed to air and water, and undergo oxidation of sulphur-based mineral (such as a pyrite). This results in the formation of sulphate and a reduction of the $\mathrm{pH}$ of the aquatic medium. The resultant acidic condition enables metals to readily dissolve in water, thus contaminating the water with high concentrations of metals such as lead $(\mathrm{Pb})$, aluminium $(\mathrm{Al})$, iron $(\mathrm{Fe})$, manganese $(\mathrm{Mn})$, and uranium (U) and causes increased acidity (McCarthy, 2011; Jennings et al., 2008). The resultant decant of AMD can cause physical, chemical and biological degradation of surface water. The problem is complex. In order to remediate AMD, many factors need to be taken into account including the geology of the mining region, the presence of microorganisms, temperature and also the availability of water and oxygen (Manders et al., 2009). Complete discussions of the formation of AMD and the problem of decant in the Witwatersrand basin are available (McCarthy, 2011; Sheridan, 2013).

\section{Acid mine drainage treatments}

\section{Active treatment systems}

Active AMD remediation includes $\mathrm{pH}$ neutralisation which normally involves the addition of alkaline compounds such as hydrated lime, limestone or quicklime, and sodium compounds such as caustic soda or soda-ash which increases the $\mathrm{pH}$ of the AMD and thereby precipitates metal ions (Chockalingam and Subramanian, 2006). Although effective in buffering $\mathrm{pH}$ and removing metal concentrations from $\mathrm{AMD}$, these chemical techniques are often costly to implement due to the costs of reagents and operations and maintenance. Furthermore, these methods result in large quantities of sludge which are difficult and costly to dispose of. If this sludge contains uranium, a host of additional problems arise.

\section{Passive treatment systems}

Passive treatment systems for AMD remediation generally do not require regular human intervention. Biological passive treatment systems used for AMD remediation normally utilise the mechanism of dissimilatory sulphate reduction (DSR) for sulphate removal (Sheridan et al., 2013) which is caused by sulphate-reducing bacteria (SRB). SRB are heterotrophic bacteria which function in an anaerobic environment. They require organic carbon to serve as an electron donor to effect sulphatereducing activity (Johnson and Hallberg, 2005). It has been established that there is a direct relationship between the rate of sulphate reduction by SRB and the amount of carbon available. Hence, organic carbon amendments are often utilised in biological passive treatment systems for AMD (Sheridan et al., 2013). Biological remediation of AMD has occurred successfully in full-scale passive treatment systems using constructed wetlands and compost bioreactors. However, Johnson and Hallberg (2005) claim that even though passive bioremediation systems involve low maintenance costs, these systems are often relatively expensive to install and may need more land area than is available or suitable. Furthermore, the performance of these systems is not as predictable as chemical remediation systems. There is also uncertainty about the long-term stability of the accumulating solid residue within passive bioremediation systems.

\section{Dissimilatory sulphate reduction (DSR)}

The process of DSR reduces sulphate to sulphide. Alkalinity is additionally produced by the generation of carbonate which also serves to raise $\mathrm{pH}$ as shown in Eq. (1).

$$
\mathrm{SO}_{4}^{2-}+2 \mathrm{CH}_{2} \mathrm{O}+2 \mathrm{H}^{+} \rightarrow \mathrm{H}_{2} \mathrm{~S}+2 \mathrm{H}_{2} \mathrm{CO}_{3}
$$

In addition to increasing the $\mathrm{pH}$ of the $\mathrm{AMD}$, the conversion of sulphate to sulphide allows removal of heavy metals from the AMD if they form insoluble sulphides (Johnson and Hallberg, 2005) as shown in Eq. 2, where $\mathrm{Me}^{2+}$ represents a divalent metallic ion.

$$
\mathrm{Me}^{2+}+\mathrm{H}_{2} \mathrm{~S} \rightarrow \mathrm{MeS}+2 \mathrm{H}^{+}
$$

In addition, as the sulphate is removed, the $\mathrm{pH}$ tends to increase, and as a result many ionic species become less soluble. This also contributes to the precipitation of heavy and other metals.

\section{Bioremediation of AMD using organic substrates as energy sources for SRB in DSR}

Previous studies have included experiments on treating AMD with organic substrates such as straw and hay (Béchard et al., 1994) and rice husk (Chockalingam and Subramanian, 2006). The organic substrates serve as the electron donor for SRB, and carboxyl and phenolic acid groups in the organic substrates attach to a larger organic molecule which binds metal ions (Chockalingam and Subramanian, 2006). Research has found that a low-cost material such as sugar cane bagasse can be utilised to passively treat AMD (Grubb et al., 2000).

Another method of passively treating AMD is by utilising constructed wetlands (Sheridan et al., 2013). Constructed wetlands provide a possible solution to the long-term treatment of acid mine drainage. Although initially expensive to construct, constructed wetlands have minimal operational requirements which can be a very important consideration for situations where there is a technical skills shortage. Constructed wetlands are designed to emulate natural wetlands, and act as biofilters to remove pollutants and toxic metals from water passing through them (Sheridan et al., 2013; Kadlec et al., 2000).

A comparison between charcoal- and slag-based constructed wetlands for AMD remediation was conducted in a previous study (Sheridan et al., 2013). Two constructed wetlands were prepared for experimentation, and AMD samples passed through them. The findings of the study indicated that constructed wetlands amended with charcoal or basic oxygen furnace (BOF) slag provided good remediation on an AMD stream. Both amendments performed similarly under the test, totally removing iron, and removing sulphate by approximately $75 \%$, while significantly increasing the $\mathrm{pH}$ of the AMD. That study is part of ongoing research into AMD remediation through the use of constructed wetlands.

Recent literature has placed emphasis on organic waste products as having potential to remediate AMD, as these 
products contain cellulose. Biological waste products are useful as an energy source for biological sulphate removal as the cellulose in these products ferments to oligomers, monomers and then VFA (volatile fatty acids) which are readily consumed by SRB (Greben et al., 2009). In Greben and co-workers' study, fermented grass cuttings in an anaerobic bioreactor were used for AMD remediation, and the study found that the system significantly reduced sulphate concentrations and had potential to treat AMD. SRB were placed in the bioreactors prior to conducting the experiment. A healthy fermentation microbial population was sustained throughout the testing period by weekly additions of grass cuttings. The organic substrate utilised was lawn grass obtained from the CSIR gardens in Pretoria, South Africa. The findings of the study indicated that up to $86 \%$ of sulphate removal could be achieved in a passive bioremediation system using fermented lawn grass cuttings as an organic substrate in the DSR process.

Lawn grass in South Africa is often not indigenous, the most popular being Pennisetum clandestinum (kikuyu), which is indigenous to east African regions. Lawn grass does not often occur naturally in mining areas and mostly needs to be cultivated. In dormant or abandoned mining locations, human activity is often minimal and therefore there may not be sources of large volumes of lawn grass available locally. Indigenous grasses, largely abundant in and around mining areas, may in some cases be a more favourable option for providing a carbon and energy source for biological AMD treatment. Indigenous grasses grow naturally to a long length and those grasses not used in agriculture or for other purposes are often cut short, rolled up and disposed of in landfills, producing methane. This waste product, which contains lignocellulose, has potential to be used as an organic substrate in biological sulphate reduction of AMD.

In this paper we formulate and test an AMD treatment using indigenous grasses as the carbon source to provide removal of iron and sulphate and neutralising of $\mathrm{pH}$, as a potentially cost-effective and environmentally sustainable solution to the acid mine drainage problem.

\section{METHODOLOGY}

\section{Bioreactor preparation}

Five $1800 \mathrm{~m} \ell$ beakers were used as bioreactors. Each beaker was filled with 1 litre of artificial acid mine water, which was prepared to contain $6000 \mathrm{mg} / \ell$ sulphate and $2000 \mathrm{mg} / \ell$ of soluble iron. This concentration was chosen on the basis of earlier artificial AMD concentrations used in our group (Sheridan et al., 2013). The iron and sulphate concentrations in each beaker were prepared by adding $25.2 \mathrm{~g}$ iron sulphate $\left(\mathrm{FeSO}_{4} \cdot 7 \mathrm{H}_{2} \mathrm{O}\right)$ and $6.5 \mathrm{~g}$ of $99 \%$ pure sulphuric acid. Caustic soda (analytical grade) was added to adjust the $\mathrm{pH}$ of the AMD in each beaker to an initial value of 3 . Four beakers served as bioreactors with organic carbon amendments and one beaker served as a control with AMD only. The beakers were placed indoors, next to a window which received sunlight during the day. Bioreactors $1,3,4$ and 5 were each filled with $50 \mathrm{~g}$ of dry indigenous grass cuttings. The grasses were cut from the bases of their stems, and the stems and inflorescences were utilised in the experiment. Two indigenous grass types were used: Hyparrhenia hirta, which was obtained from the roadside in Auckland Park, and Setaria Sphacelata, obtained from the garden of the Origins
Centre on the University of the Witwatersrand's main campus. The plants were identified at the herbarium of the University of the Witwatersrand, Johannesburg.

The following experiments were prepared:

- Beaker 1: Hyparrhenia hirta and AMD solution (HH)

- Beaker 2: AMD solution control (Control)

- Beaker 3: Hyparrhenia hirta and Zantedeschia aethiopica growing in the AMD solution (HHZ)

- Beaker 4: Hyparrhenia hirta with attached soil from a Zantedeschia aethiopica root and AMD solution (HHM)

- Beaker 5: Setaria sphacelata and AMD solution (SS)

The experiments were designed to test the following:

- Comparison of the effectiveness of grass species in remediating AMD

- Comparison of grasses with actively growing plants placed within the beaker

- Comparison of actively growing plants with root zone substrate added to determine if the addition of bacteria would enhance remediation

\section{Data collection}

Sampling of the bioreactors took place over a period of 70 days, initially every 3-4 days, thereafter every 1-2 weeks during the final 4 weeks (Day 40 to Day 70). The sampling period occurred between March and May 2012. Bioreactors were topped up every 3-4 days to keep all solution volumes constant, after sampling, and to eliminate evaporation losses.

\section{Chemical analysis}

Iron concentration was tested using a Merck Photometer with Merck Reagent kit (SQ118); sulphate concentration was tested using a Shimadzu UV-Visible Spectrometer (UV-1601). We tested for sulphate by adding barium chloride, forming barium sulphate which is insoluble. Sulphate ions were allowed to precipitate in an acid medium with barium chloride $\left(\mathrm{BaCl}_{2}\right)$ so as to form crystals of barium sulphate $\left(\mathrm{BaSO}_{4}\right)$ of uniform size. A photometer was used to measure light absorbance of the $\mathrm{BaSO}_{4}$ suspension, and the $\mathrm{SO}_{4}{ }^{2-}$ concentration was then determined by comparison of the reading with a standard curve.

\section{RESULTS AND DISCUSSION}

\section{PH ADJUSTMENT}

Figure 1 represents the $\mathrm{pH}$ in each bioreactor over the 70-day experimental period.

The data indicate that the $\mathrm{pH}$ of the AMD in bioreactors with organic substrates increased during the 70-day period. The $\mathrm{pH}$ of the control decreased slightly, and remained relatively constant from Day 28 onwards. This indicates that it was indeed the organic substrates in Bioreactors 1, 3, 4 and 5 that caused the increase in the $\mathrm{pH}$ values of the solution in them. It can be seen that for Bioreactors 1, 3, 4 and 5 the slope of the graph rises and then plateaus. The best performance was found in Bioreactor 4 (with Hyparrhenia hirta and microbes) where the resultant $\mathrm{pH}$ was quite high at approximately 8.5. The worst performance was found in Bioreactor 1 (with Hyparrhenia hirta only), although this still showed significant performance in comparison to the control. 


\section{Iron removal}

The data showing the removal of iron are presented in Fig. 2. Over the 70-day experimental period, the greatest amount of iron reduction occurred in Bioreactor 4 (HHM), which obtained $98 \%$ iron reduction. Bioreactor 3 (HHZ) performed similarly, achieving $97 \%$ iron removal by 70 days. Bioreactor $1(\mathrm{HH})$ removed $54.5 \%$ of iron from the AMD. Bioreactor 5 (SS) provided greater iron reduction than Bioreactor 1 over the 70 -day experimental period, removing $32 \%$ more iron. The sharp increase and then decrease in concentration of Bioreactor 3 (HHZ) (Fig. 2), between Days 11 and 18 is attributed to experimental error and therefore was not considered a significant finding of the experiment.

The plant addition in Bioreactor 3 (HHZ) had a significant positive impact on iron removal. Iron removal in Bioreactor
3 was $43 \%$ more than in Bioreactor 1 (which had Hyparrhenia hirta only). Research conducted by others (Kalin et al., 2006), indicated that plants can be used in AMD remediation systems to act as stabilisers of accumulating ferric precipitates. The plant in Bioreactor 3 may have provided additional surface area for solid ferric iron compounds to precipitate. In addition, the fermentation of the plant parts could have provided a carbon and energy source for further bacterial growth, facilitating the DSR process. During the experimental period, it was observed that the plant died by Day 33 and thus its parts would have added extra cellulose to the reactor. We find it astonishing that a plant could survive for such a long period in such hostile conditions and we plan further research to investigate the tolerance of difference plant species to the acidic environment of AMD in order to determine the most suitable plant species for AMD treatment application.

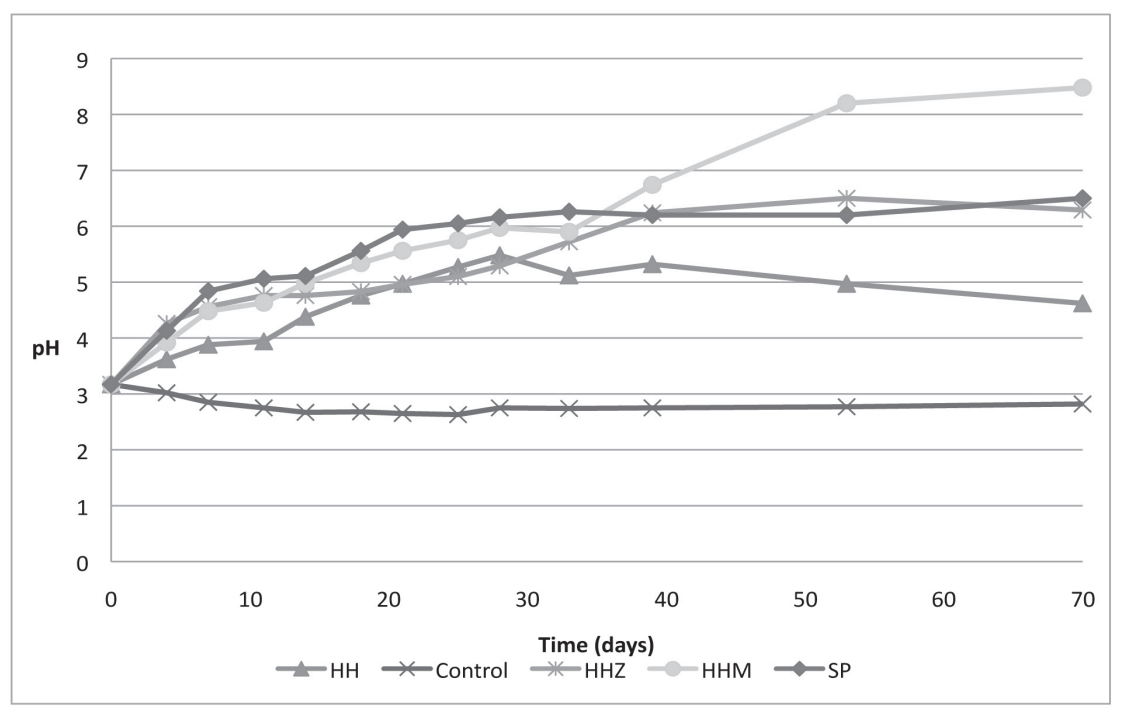

Figure 1

A comparison of the $\mathrm{pH}$ of AMD water in the active (with grass amendments) and control bioreactors as a function of time

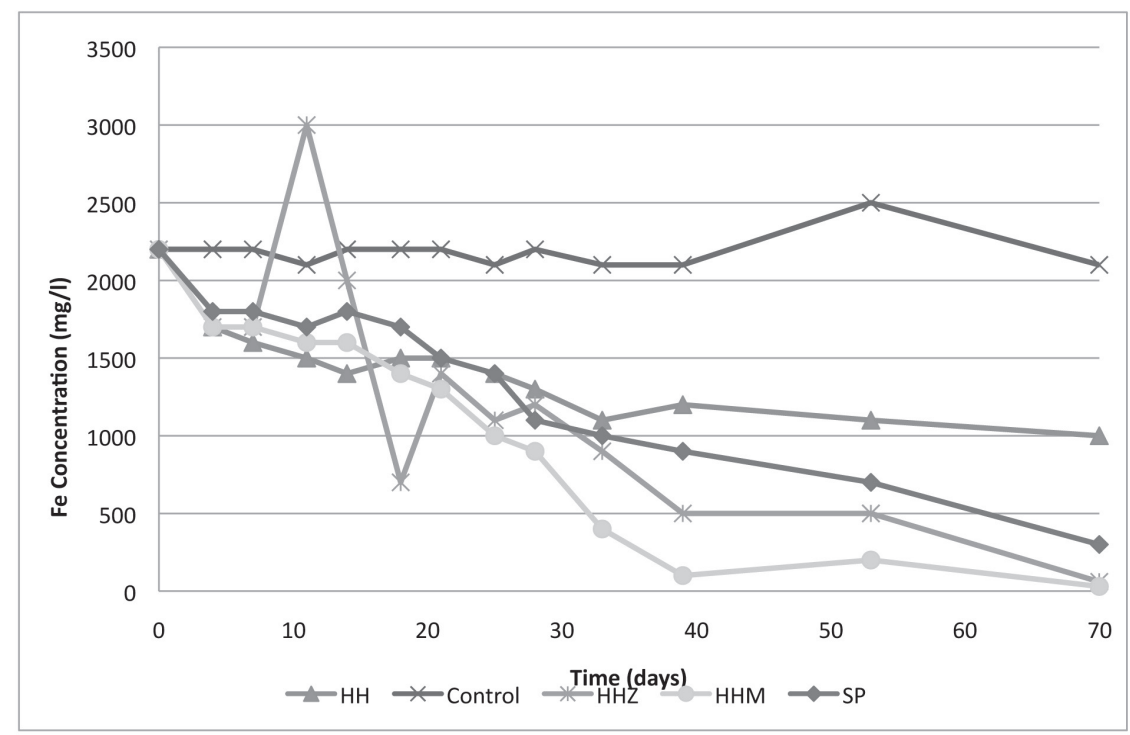

Figure 2

A comparison of the iron concentration of AMD water in the active (with grass amendments) and control bioreactors as a function of time 


\section{Sulphate removal}

The removal of sulphate from the bioreactors is shown in Fig. 3. Bioreactors 1 (HH), 3 (HHZ), 4 (HHM) and 5 (SS) all show a trend of decreasing sulphate concentration over the 70-day experimental period, whereas the control did not show any significant decrease throughout the experimental period. This indicates that the grass effected sulphate reduction in all experiments. The sharp increase and then decrease in the concentration of sulphate in Bioreactor 3 between Day 11 and Day 18 is likely an experimental error and is thus ignored. In all bioreactors there was a strong smell of rotten eggs which indicated the presence of hydrogen sulphide $\left(\mathrm{H}_{2} \mathrm{~S}\right)$. This indicates that the mechanism of sulphate removal was indeed DSR. The best sulphate reduction occurred in Bioreactor 4 (HHM), removing $80 \%$ of sulphate from the AMD solution to achieve a residual sulphate concentration of $1240 \mathrm{mg} / \ell$. Its performance is attributed to the mixture of grass and soil with microbes. These findings are concurrent with previous research (McCauley et al., 2009) where sulphate reduction was found to be most effective when incorporating a mixture of organic substrates and microbes as opposed to using a single substrate. Consistent with other research (Wildeman et al., 2006), it was shown that it is advantageous to include an SRB inoculum such as soil or sludge from an anaerobic environment.

A numerical summary of the experimental results is presented in Table 1 to demonstrate the percentage removal of the different components of the AMD.

\section{CONCLUSIONS}

The experimental data presented in this paper lead us to believe that there is significant potential for using grass as the electron donor for AMD remediation through the process of DSR. All experiments raised the $\mathrm{pH}$ and also removed iron and sulphate from the artificial AMD solutions. The addition of soil from the root-zone of the wetland plant Zantedischia aethiopica enhanced the remedial capacity of our bioreactors and we hypothesise that this is due to the addition of sulphatereducing bacteria to our reactors. Following remediation, the bioreactors contained an iron-rich sludge, the disposal of which will require careful thought and planning should the strategy presented here ever be used for large-scale AMD remediation.

Future research will need to consider the full life cycle of potential treatment plants including the safe disposal of the byproducts of AMD remediation systems. The method of sludge disposal needs to be examined, and a sustainable solution sought. Future studies to determine the tolerance of plants to the artificial AMD will also need to be conducted.

\section{REFERENCES}

BÉCHARD G, YAMAZAKI H, GOULD WD and BÉDARD P (1994) Use of cellulosic substrates for the microbial treatment of acid mine drainage. J. Environ. Qual. 23 (1) 111-116.

CHOCKALINGAM E and SUBRAMANIAN S (2006) Studies on removal of metal ions and sulphate reduction using rice husk and

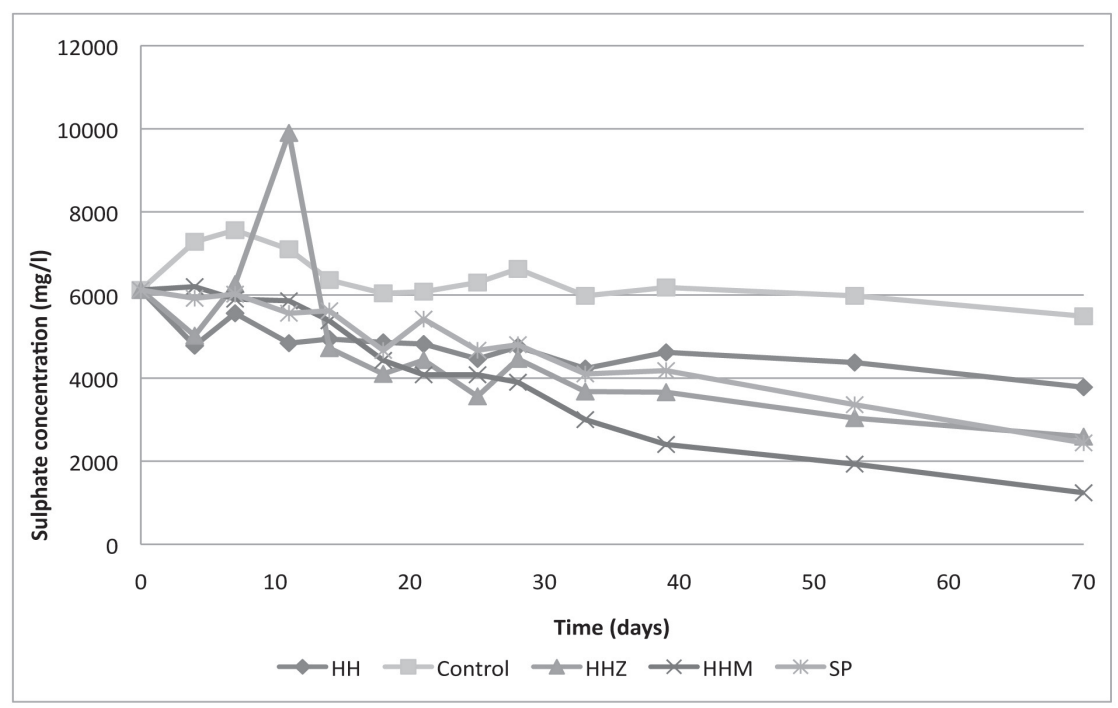

Figure 3

A comparison of the sulphate concentration of AMD water in the active (with grass amendments) and control bioreactors as a function of time

TABLE 1

Summary of final $\mathrm{pH}$, percentage iron removal and percentage sulphate removal for each bioreactor in the experiment

\begin{tabular}{|l|c|c|c|}
\hline Bioreactor & Final $\mathbf{~ H ~}$ & \% Fe Removal & \% SO $_{\mathbf{4}}{ }^{2-}$ Removal \\
\hline $1(\mathrm{HH})$ & 4.62 & 54.5 & 38.2 \\
\hline $2(\mathrm{Control})$ & 2.82 & 4.5 & 10.3 \\
\hline $3(\mathrm{HHZ})$ & 6.29 & 97.2 & 57.7 \\
\hline $4(\mathrm{HHM})$ & 8.48 & 98.6 & 79.7 \\
\hline $5(\mathrm{SS})$ & 6.5 & 86.4 & 60.1 \\
\hline
\end{tabular}


Desulfotomaculum nigrificans with reference to remediation of acid mine drainage. Chemosphere 62 (5) 699-708.

COETZEE H, HOBBS PJ, BURGESS JE, THOMAS A, KEET M, YIBAS $B$, VAN TONDER D, NETILI F, RUST V, WADE P and MAREE J (2010) Mine water management in the Witwatersrand Goldfields with special emphasis on acid mine drainage: Report to the InterMinisterial Committee on Acid Mine Drainage, South Africa.

GREBEN H, SIGAMA J, BURKE L and VENTER S (2009) Cellulose fermentation products as an energy source for biological sulphate reduction of acid mine drainage type wastewaters. WRC Report No. 1728/1/08. Water Research Commission, Pretoria.

GRUBB DG, LANDERS DG and HERNANDEZ M (2000) Utilisation of sugarcane bagasse to treat acid mine drainage. In: ISRM International Symposium, 19-24 November 2000. Melbourne. CRC Press, Boca Raton, USA.

JENNINGS SR, NEUMAN DR and BLICKER PS (2008) Acid mine drainage and effects on fish health and ecology: A review. Reclamation Research Group Publication, Bozeman, MT.

JOHNSON DB and HALLBERG KB (2005) Acid mine drainage remediation options: a review. Sci. Total Environ. 338 (1-2) 3-14.

KADLEC RH, KNIGHT RL, VYMAZAL J, BRIX H, COOPER P and HABERL R (2000) Constructed Wetlands for Pollution Control: Processes, Performance, Design and Operation. IWA Scientific and Technical Report No. 8. IWA Publishing, London.

KALIN M, FYSON A and WHEELER WN (2006) The chemistry of conventional and alternative treatment systems for the neutralization of acid mine drainage. Sci. Total Environ. 366 (2) 395-408.
MANDERS P, GODFREY L and HOBBS P (2009) Acid mine drainage in South Africa. Briefing note 2009/02. CSIR Natural Resources and the Environment, South Africa.

MCCARTHY TS (2011) The impact of acid mine drainage in South Africa. S. Afr. J. Sci. 107 (5-6) 01-07.

MCCAULEY CA, O'SULLIVAN AD, MILKE MW, WEBER PA and TRUMM DA (2009) Sulphate and metal removal in bioreactors treating acid mine drainage dominated with iron and aluminum. Water Res. 43 (4) 961-970.

NECULITA C, ZAGURY GJ and BUSSIERE B (2007) Passive treatment of acid mine drainage in bioreactors using sulphate-reducing bacteria. J. Environ. Qual. 36 (1) 1-16.

SHERIDAN CM, HARDING K, KOLLER E and DE PRETTO A (2013) A comparison of charcoal- and slag-based constructed wetlands for acid mine drainage remediation. Water SA 39 (3) 369-374.

SHERIDAN C (2013) Paying the price. The Chemical Engineer (867) $30-32$.

SMITH K (1997) Constructed wetlands for treating acid mine drainage. Université du Minesota-Etats-Unis Departement d'Horticulture. URL: http://horticulture.coafes.umn.edu/vd/ h5015/97papers/smith.html (Accessed 3 September 2014).

WILDEMAN T, GUSEK J and HIGGINS J (2006) Passive treatment of mine influenced waters. In: Course material for the ARD Treatment Short Course presented at: 7th International Conference on Acid Rock Drainage (ICARD), 25-30 June 2006, St. Louis, MO, USA. 